\title{
A Comparison of Reading Levels of High School and Freshmen University Students in Jordan
}

\author{
Nasser M. Freahat \\ Faculty of Languages and Translation, Al-Imam Mohammad Ibn Saud Islamic University, Saudi Arabia
}

\begin{abstract}
This study aimed to analyze the readability, appropriateness and difficulty level of the reading texts in Action Pack 11 (hereafter AP11) which is taught for grade 11, Action Pack 12 (hereafter AP 12) that is taught for grade 12 at the schools of The Jordanian Ministry of Education and New Headway Plus Pre-intermediate (hereafter $N H W P$ ) that is taught for an introductory English language course in the Jordanian Universities. The sample of the study involved 274 eleventh grade students, 300 twelfth grade students, and 310 freshmen students who were studying CL 099 at Yarmouk University in the academic year 2011/2012. The study employed Flesch Grade Level and Flesch Kincaid Reading Ease formulas to identify the readability level of each textbook. Furthermore, a sixth- word deletion cloze test version of a representative text from each textbook was used to identify the match between the textbooks and the students. The findings of the study revealed that the secondary school textbooks are on average about three grade levels higher in reading difficulty than the textbook of the university level. Furthermore, the cloze test results showed that the majority of the students studying each textbook were at their frustration reading levels.
\end{abstract}

Index Terms—readability, reading difficulty, transition to postsecondary reading

\section{BACKGROUND}

It is essential that the difficulty of the textbook is appropriate for the reading abilities of the students for whom the books are intended. When matching readers to texts, there are two main intuitions. First, texts can be ordered according to the difficulty each presents for a reader. Second, readers can be assessed according to the success each will have with any particular text. Assessing the difficulty of the text and the level of the reader are necessary so that the right book can be matched to the right reade. Renaissance learning (2011) points out that matching reading materials to students is a four-step process which involves 1) estimating text readability, 2) measuring students' level of reading achievement, 3) determining the appropriate reading range, and 4) continuously monitoring comprehension and adjusting book levels and genres. However, the persistent question is what the best match between the students' level of reading and the level of readability should be.

Texts that are difficult to read usually have high readability levels; those that are easy to read have low readability levels. According to Harrison (1980), readability is the way in which we measure the relative level of difficulty of the reading material. Because many students experience difficulty with reading the textbook, readability formulas, cloze tests, and other means are utilized to determine whether or not the textbook is appropriate for a particular grade level. Crawly and Mountain (1995: P22) believe that "the readability level should be the determining factor in choosing a particular book".

There are a variety of different methods and approaches that can be used for assessing the readability levels of reading materials. The most common approach in assessing readability is the use of readability formulas. These formulas provide educators with an estimate of the difficulty of books and other texts. Most readability formulas incorporate two components semantic difficulty and syntactic difficulty. Examples of these readability formulas are Flesch Reading Ease Formula, Flesch-Kincaid Formula, SMOG Formula, Dale- Chall Formula, Spache Formula, Forcase Formula, Fry Formula, and RIX Formula.

Flesch Reading Ease and the Flesch- Kincaid formulas are appropriate for all reading levels and are available in Microsoft Word which makes them especially easy to use for whole documents. The Flesch Reading Ease score is a numerical value between 0 and 100. The higher the Flesch Reading Ease score, the greater the number of people who can comprehend the document easily. Flesch-Kincaid, on the other hand, converts the Flesch Reading Ease score into a grade-level score. This formula also relies on sentence length and word difficulty to calculate a readability level. An interesting alternative to traditional readability formulas is the cloze procedure. In cloze tests a passage is prepared by removing every nth word (usually every fifth word) and subjects of known reading age are asked to supply the missing items. The percentage of words correctly entered is the cloze score. The lower the score, the more difficult the text is. The cloze test estimates how well each student functions when they interact with the text.

During the transition from secondary to postsecondary education, students deal with many changes like the new level of education requirements. Although secondary school students may be able to successfully study their school course content, they may not be prepared to deal with the difficulty of the texts they encounter in the postsecondary stage. The alignment between the reading demands of the secondary school and those of the postsecondary education may 
facilitate the transition for many students. Therefore, educators should strive to achieve alignment between the teaching demands of the school and those of the university.

Venezia, Krist, and Antonio (2003) provided an evaluation of the conditions that characterize the transition from high school to college. They stated that,

[h]igh school assessments often stress different knowledge and skills than do college entrance and placement requirements. Similarly, the coursework between high school and college is not connected; students graduate from high schools under one set of standards and, three months later, they are required to meet a whole new set of standards in college. Current data systems are not equipped to address students' needs across systems, and no one is held accountable for issues related to student transition from high school to college. (p.1)

Chall (1983) presents a detailed understanding of the distinction between teaching reading in different academic stages. He believes that high school students need to learn to read for multiple viewpoints, which include critical reading for comprehension of various ideas presented in the text. At this level of reading, basic facts and ideas are presented, then additional facts and ideas from opposing or corresponding views are also given. The high school reader must connect various facts and ideas to gain complete understanding of the text. College students, on the other hand, should read to construct and reconstruct ideas, including comprehension through analyzing, synthesizing, and evaluating information presented by the author. This stage of reading development forces the reader to master selective reading skills. When readers have broad general knowledge of the text, they read quickly, analyzing, synthesizing, and evaluating as they speed through the text.

The secondary school provides the last opportunity for most students to obtain guidance in reading proficiency. Macklin (1978) indicates that reading instruction at the secondary level might be perceived as helping the reader to acquire information and develop specific techniques needed for handling the reading materials in each discipline. Roe, Stoodt and Burns (1978) report that secondary level textbooks in various areas tend to have high readability levels in relation to the reading abilities of the students who are expected to read them. They add that evidence indicates that a wide variety of difficulty exists within single texts and that many texts do not have a gradation of difficulty from the beginning to the end.

The teaching of English as a Foreign Language in Jordan aims at developing different language skills. As a natural learning environment is unavailable for Jordanian readers, the major source for students to acquire reading is through classroom instruction of the assigned EFL textbooks. A large number of freshman university students in Jordan complain about the difficulty of the reading component in EFL courses. In spite of the educational and financial support, there is an observable weakness on the part of students in the reading comprehension skills. On the other hand, Jordanian universities have a series of compulsory courses which all aim to improve the students' ability in the four main skills: reading, writing, listening and speaking. One of these courses is the English course LC 099 which is the first introductory EFL course students study at the university. Moreover, many English language instructors in the Jordanian universities complain that many of their students are poor readers. In spite of all the changes that are taking place in the Jordanian educational system, there is an observable weakness in reading comprehension skills on the part of the students. This deficiency in reading comprehension may be attributed to many factors among which is the reading material and how reading is presented in the textbooks at high school and university.

\section{REVIEW OF LITERATURE}

\section{Studies Related to Transition to Postsecondary Reading}

Many studies were conducted on the students' transition to postsecondary endeavors. Specifically, some studies were conducted on how high school prepares students to read in the postsecondary endeavors. ACT (2006) tested the reading comprehension skills of approximately 1.2 million high school students, who graduated in 2005 across the United States to investigate the preparedness of the tested students to the college level reading demands. The results of the test indicated that only $51 \%$ of the high school graduates were ready for college-level reading.

Two years later, Williamson (2008) examined whether 11th- and 12th-grade students' exposure to high school texts sufficiently prepares them for textual material they might encounter in their postsecondary endeavors. He used the Lexile Framework for Reading to determine text readability measures. The study investigated 175 textbooks at the high school grades, 100 textbooks of university textbooks, 50 textbooks representing community college textbooks, reading materials from the U.S. Army Web site, 1,400 examples of occupational reading material, and various materials representing different aspects of citizenship. The study demonstrated that high school material reflected a substantially higher text demand from students in the postsecondary lives.

In a try to compare the extent to which high school prepares students for university reading level, Wilkins, Hartman, Howland, and Sharma (2010) used the Lexile Framework for Reading to determine the proportion of grade 11 Texas public school students who indicate the ability to read and comprehend 74 textbooks used in entry-level English courses at the University of Texas. The results of the study showed that about half of public school students in grade 11 in Texas were prepared to read at the University of Texas system.

Sidek (2011) examined how well the Malaysian EFL secondary reading curriculum prepares students for tertiary reading in English. The findings indicated that the curriculum only partially prepares secondary school students for tertiary reading in EFL. 
To conclude, the several aspects of this transition were studied in the reading field. These aspects mainly included the effect of university introductory EFL courses, high- school students' preparedness for college level reading demands, reading skills taught at high school and those expected of incoming students by instructors of common first year college courses, and the proportion of high school students who can read and comprehend entry-level English courses. These studies came out with an endless list of findings.

\section{Second: Studies Related to Matching Books to Students}

Educators have long been engaged in ongoing research to find reading materials at an appropriate level of difficulty for their students. This part reports some studies which were concerned in the idea of matching textbook readability to students' reading ability.

Harris- Sharples (1983) investigated the relationship between the difficulty levels of social studies, science, and reading textbooks used in $4^{\text {th }}, 5^{\text {th }}$, and $8^{\text {th }}$ grade classrooms, and the reading skills of the students who used them. The study used the Dale-Chall formula to assess the readability of the textbooks. Moreover, 162 students were tested with cloze passages to gather judgments of difficulty. The study found that the readability levels of the reading textbooks were found to be lower than those of content subjects; they were below students' grade placements.

Using the Nelson-Denny Reading Test and the Fry readability Formula, Reed (1987) compared the average reading ability of freshmen students enrolled at an open door community college with the readability levels of eight content area textbooks used in courses at the college. The findings indicated that the readability levels of the eight textbooks were above the mean readability score of the students tested.

In the same year, Sellars (1987) examined the appropriateness of the textbooks used in tenth, eleventh, and twelfth grade social studies, science, and literature classes from four different public high schools in Florida. The study also compared the difficulty of textbooks in each content area. An exact word scored cloze test was administered to determine the difficulty of the textbooks. The results indicated that $92 \%$ of the tested students were at the frustration reading level, which means that only 8 percent of the subjects were able to profit from attempting to read these textbooks.

Browne (1996) investigated the readability level of 12 Japanese university-level EFL reading textbooks. The reading difficulty of the textbooks was analyzed via four readability formulas (Flesch Reading Ease, Flesch Kincaid Scale Grade, Coleman-Lian Grade Level, and Bormuth Reading Ease). The study found that college reading textbooks produced by Japanese publishers seemed to vary tremendously in level, with most texts far above the reading ability of the Japanese college students. Moreover, High school reading texts appeared to be even more difficult in terms of readability than the college texts. It was also found that none of the reading materials produced in Japan gave any direct indication about the level of the material.

In the Jordanian situation, Masri (2006) investigated the readability level of the tenth grade EFL textbook (Jordan Opportunities) in reference to the reading abilities of the $10^{\text {th }}$ grade students in Jordan. The researcher used a 250 word long fifth word deletion cloze test to assess the readability of the textbook. The results of the study showed that the readability level of Jordan Opportunities was in the frustration level, which means that the students were not able to understand the passages even with the help of the teacher.

In the same year, Ulusoy (2006) investigated the match between the Ankara's middle class science and social studies textbooks and the students' reading levels. 275-300 word long $6^{\text {th }}$ word deletion versions of cloze-test passages were prepared. Cloze test results showed that half of the students were reading materials at their instructional levels, and these students needed help to understand the passages.

More recently, Abdulla and Hashim (2007) examined the readability statistics of 12 Malaysian short stories and seven short stories written by English native speakers. The analyzed short stories had been recommended as texts for the English literature syllabus in the Malaysian secondary school curriculum. The study used three readability statistics (Flesch Reading Ease, Flesch Grade level, and Gunning Fog Index) for analyzing the stories. The analysis revealed that both the Malaysian stories and the stories written by native speakers fall within the range of U.S. grade 6.6-8.5.

Most recently, Tabatabaei and Bagheri (2013) examined the readability indixes of reading passages of English textbooks taught at Iranian high schools. The study also examined the students' prior knowledge-interest levels to see to what extent students were interested or had background knowledge regarding reading passages in their English textbooks. The results showed that the students almost had a low level of interest and background knowledge regarding reading passages in their English textbooks. The findings also showed an insignificant relationship between students' interest level and readability indexes of the passages.

Studies in this specific field mainly compared the textbook readability with the average reading ability of the students. For identifying students' reading ability, the studies used cloze tests, comprehension tests, and Nelson-Denny Reading test. On the other hand, the studies used many instruments for identifying textbook readability. These instruments included Dall-Chall, Lorge, Bormuth Reading Ease, Flesch, Flesch Kincaid, Fr, Grah, Gunning, Coleman-Lian Grade Level, and Raygor. The studies concluded many findings. In most cases, the readability levels of the textbooks were far above the mean reading ability scores of the students. Some studies showed that university professors and school teachers do not take into consideration the readability levels of textbooks, and that they should consider using readability sources when they make decisions concerning textbook adaptations. Furthermore, research studies related to textbook difficulty and matching textbooks to students indicated that most of the analyzed textbooks were far too 
difficult for the level of the students. Furthermore, the readability formulas, the cloze test, and checklists can be used to determine the match between students and books. Moreover, the reading difficulties of students making the transition to postsecondary education complicate their ability to be successful in their academic progress. One of the most commonly cited reasons behind these difficulties is poorly written reading textbooks.

\section{Statement of the Problem}

In Jordan, many university students, after studying English for twelve years at school, suffer real problems because of the new demands placed on them. To ascertain whether there is a textual gap or not it requires that the content of textbooks prescribed for students be analyzed. This means that a percentage of university students is somehow unable to conform to the situation at the university. Hussein (2012) maintains that Jordanian first year students lack many "reading comprehension skills". For instance, he complains that, they lack the ability to answer questions that demand the possession of skills involving deep thinking. He adds that little attention is given to skills which belong to inferential and critical levels. The deficiency in the students' reading can be attributed to different factors including the preparation of the students at school and the gap between the school and the university textbooks. To ascertain whether the gap is purely a performance gap or whether there is also a textual gap requires that both students' performance and textual difficulty be studied.

\section{Objective of the Study}

This study aimed at finding out how the secondary school EFL curriculum in Jordan prepares students for university level reading skills. In other words, the study aimed to analyze the appropriateness and the difficulty level of the reading content in Action Pack 11 (hereafter AP11) which is taught for grade 11, Action Pack 12 (hereafter AP 12) that is taught for grade 12 at the schools of The Jordanian Ministry of Education and New Headway Plus Pre-intermediate (hereafter NHWP) that is taught for an introductory English language course at Yarmouk University (LC 099). The study also aimed to compare the readability level of reading material in the Jordanian high school EFL textbooks to that of the introductory EFL course textbooks in the Jordanian Universities.

The following research questions were to be answered through this study:

1. How does the readability of the reading passages of the Jordanian high schools compare with that of the university introductory EFL courses in Jordan?

2. How does the match between NHWP readability and the reading performance of LC 099 students compare with the match between the readability of $A P 11$ and the reading performance of Grade 11 students, and the readability of $A P$ 12 and grade 12 students' reading performance?

\section{METHOD}

\section{A. Participants}

The researcher followed the cluster sampling technique where three clusters were identified $\left(11^{\text {th }}\right.$ grade students, $12^{\text {th }}$ grade students, and CL 099 students). Sections were purposefully assigned from each cluster. The first group was 274 eleventh grade students (148 females and 126 males). Four sections in four public female schools and four sections in four public male schools were chosen purposefully.

The second group was 300 twelfth grade (163 females and 137 males). Four sections in four public female schools and four sections in four public male schools were chosen purposefully. Table 1 below shows the distribution of the $11^{\text {th }}$ and $12^{\text {th }}$ grade students samples.

TABLE 1:

\begin{tabular}{lllllll}
\multicolumn{6}{l}{ THE DISTRIBUTION OF THE $11^{\mathrm{TH}}$} & AND $12^{\mathrm{TH}}$ GRADE STUDENT PARTICIPANTS. \\
\hline Level & Gender & Scientific & Literary & IT & $\begin{array}{l}\text { Heath } \\
\text { Management }\end{array}$ & Total \\
\hline 11th & Male & 31 & 33 & 35 & 27 & 126 \\
Grade & Female & 37 & 33 & 41 & 37 & 148 \\
\hline 12th & Male & 33 & 36 & 37 & 31 & 137 \\
Grade & Female & 37 & 41 & 43 & 42 & 163 \\
\hline
\end{tabular}

The third group was 310 freshmen students who were studying CL 099 at Yarmouk University Language Center during the first semester of the academic year 2011/2012 (183 females and 127 males). Six sections at Yarmouk University language centre were purposefully assigned for the purpose of this study.

\section{B. Instruments of the Study}

The following instruments were used in the study to collect the data:

\section{A). Readability Statistics}

To determine the difficulty levels of the reading texts in AP 11, AP12, and NHWP the researcher used Microsoft ${ }^{\odot}$ Word 2007 to calculate the readability statistics of the reading texts. According to Microsoft ${ }^{\odot}$ Word 2007 help guide, the Flesch reading Ease Readability Score can be interpreted according to the range in Table 2 below. 
TABLE 2:

FLESCH READING EASE SCORE MAPPING TABLE

\begin{tabular}{ll}
\hline Score Range & Readability Level \\
\hline $00-29$ & Very difficult \\
$30-49$ & Difficult \\
$50-59$ & Fairly difficult \\
$60-69$ & Standard \\
$70-79$ & Fairly easy \\
$80-89$ & Easy \\
$90-100$ & Very easy \\
\hline
\end{tabular}

Flesch Kincaid Grade rates texts on school grade level. For example, a score of 8.0 means that an eighth grader can understand the document. Microsoft ${ }^{\circledR}$ Word 2007 also provides additional counts and averages.

Additional statistics provided by the program include three count figures and three averages. Although the count data by itself does not give much information about the difficulty of a passage, these counts (number of words, paragraphs, and sentences) are most likely given because they provide the raw data necessary to calculate the averages and readability indexes. The three averages (sentences/ paragraph, words/ sentence, and character/ word) offer another way of comparing the relative reading difficulty of different texts, with higher number indicating higher difficulty.

All texts in the three textbooks were typed on Microsoft ${ }^{\circ}$ Word 2007 then they were analyzed and average statistics of Flesch Reading Ease and Flesch- Kincaid Grade Level were calculated. Then the results were tabulated and comparisons between the three textbooks were made in light of the readability statistics.

\section{Choice of the textbooks for analysis}

For a number of reasons, the reading content in grade 11, grade 12, and LC 099 were chosen as the levels of textbooks to analyze. Grade 11 and 12 make the secondary stage in the Jordanian educational system. On the other hand, LC 099 is the first EFL course that the majority of the university freshmen study if compared to other courses. The period including the secondary stage and university first year represents the transition from school to university. The researcher was interested in this stage when he planned his research as this stage is a crucial one in the students' academic life and it has not been studied earlier as shown by the literature review. Therefore, it is hoped that this study presents an insightful reading into some aspects of this stage by investigating the appropriateness and the difficulty level of the reading content in the textbooks under study.

\section{B). The Cloze Test}

To determine the match between the reading content of the textbooks and the students' reading levels, 275- 324 word long passages were selected from AP 11, AP 12, and NHWP to create cloze test passages (Appendix B). The first and the last sentences of the passages were left intact, and beginning with the second sentence, every sixth word was deleted. If the sixth word was a proper noun, it was skipped and the next word was deleted. In addition to being unseen by the students, the cloze passages were chosen on the basis of the difficulty of the texts. The text which had its difficulty level as the closest to the average difficulty level of the textbook was chosen. That's why there was some variation in the number of deletions in each cloze passage.

\section{Reliability of the Cloze Test}

To establish reliability, the cloze test passages were applied on one classroom from each level using the test-retest method. The reliability and the stability of the cloze tests were calculated by using Kurder- Richardson 20 . The internal consistency scores ranged between 0.78 and 0.91 whereas the stability scores ranged between 0.84 and 0.92 . These scores are considered high in terms of establishing test reliability.

\section{Difficulty and Discrimination of the Cloze Test}

Difficulty and discrimination coefficients were calculated for each cloze test. The difficulty coefficients for the Action Pack 11 cloze test ranged between 0.29 and 0.72 while the discrimination coefficients ranged between 0.42 and 0.80 . The difficulty coefficients for the Action Pack 12 cloze test ranged between 0.28 and 0.54 while the discrimination coefficients ranged between 0.44 and 0.82 . The difficulty coefficient for the New Headway Plus Pre-intermediate cloze test ranged between 0.25 and 0.51 while the discrimination coefficients ranged between 0.40 and 0.81 .

\section{Data Analysis}

Analyzing the data obtained in the second part question required comparisons of the averages of the readability statistics of the three textbooks. The readability statistics of the three textbooks were tabulated and compared. The analysis of the data of the second question required comparisons of the means and percentages from cloze test scores on the three different textbooks. The percentages, frequencies, and means of the correct responses were calculated. Only the exact answers were scored for the cloze tests (not synonyms).

\section{RESULTS}

\section{First: Results related to the first research question:}

To determine the difficulty of the reading content, readability statistics for the reading passages in the three textbooks were calculated using the readability tools available on Microsoft ${ }^{\Theta}$ Word 2007. Table 3 presents the results of the readability analysis of the reading passages in $A P 11, A P 12$, and $N H W P$. 
TABLE 3:

READABILITY STATISTICS FOR AP11, AP12, AND NHWP

\begin{tabular}{|c|c|c|c|}
\hline \multirow{2}{*}{\multicolumn{4}{|c|}{ 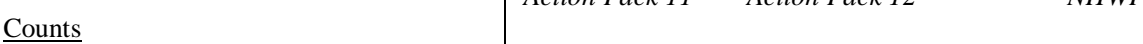 }} \\
\hline & & & \\
\hline Words & 270 & 260.8 & 320.2 \\
\hline Characters & 1301 & 1216 & 1428.5 \\
\hline Paragraphs & 5 & 4 & 7.5 \\
\hline Sentences & 14.9 & 13.5 & 27.9 \\
\hline \multicolumn{4}{|l|}{ Averages } \\
\hline$\overline{\text { Sentences/Paragraph }}$ & 3.5 & 3.6 & 4.7 \\
\hline Words/Sentence & 18 & 18.9 & 12.0 \\
\hline Characters/word & 4.5 & 4.4 & 4.3 \\
\hline \multicolumn{4}{|l|}{ Readability Indexes } \\
\hline Passive sentences & $19 \%$ & $8 \%$ & $7 \%$ \\
\hline Flesch Reading Ease & 60.8 & 58.6 & 75.0 \\
\hline Flesch Kincaid Grade & 9.2 & 9.5 & 5.76 \\
\hline
\end{tabular}

Table 3 is ordered from left to right in order of the expected difficulty. That is, it is assumed that AP11 should be easier than AP12, and AP12 should be easier than NHWP. Surprisingly, a comparison of the three textbooks shows that the secondary school textbooks (AP11 and AP12) are, on average, about three grade levels higher in reading difficulty than the textbook of the university level $(N H W P)$. The Flesch Kincaid Grade Level statistics rate AP11 and AP12 in the ninth grade reading level with $A P 12$ being more difficult whereas $N H W P$ is rated in the fifth grade level. On the other hand, the Flesch Reading Ease Formula rates the three textbooks in the following order, AP11: Standard, AP12: fairly difficult, and $N H W P$ : fairly easy.

The count figures show that $N H W P$ had the longest passages of the three textbooks, on average, and APII had longer passages than AP12. The average statistics show that NHWP had the longest paragraphs, AP12 had the longest sentences, and AP11 had the longest words. Furthermore, the readability statistics show that APII had the largest percentage of passive sentences.

It is worth pointing out that readability scores for the texts also varied tremendously within each textbook, and that neither of the textbooks followed a systematic pattern in presenting the passages in the textbooks according to their difficulty. Flesch Grade Level score for the reading texts in APII varied among the textbook. The estimated grades for the reading passages ranged from 4.9 (Grade Four) to 10.9 (Grade ten). The presentation of these passages does not follow a certain pattern as it begins almost with the most difficult passage and ends with below-the-level passage.

Similarly, Action Pack 12 did not follow a certain pattern in presenting the reading passages in the textbook according to their difficulty level. Table 3 shows the Flesch Grade Scores for all texts of AP11 as they appeared in the textbook. Flesch Grade Level scores for the reading texts in AP12 varied among the textbook. The estimated grades for the reading passages ranged from 5.8 (Grade Five) to 10.5 (Grade ten). The presentation of these passages does not follow a certain pattern as it begins almost with the most difficult passage (10.2,11.4, and 12.6) and ends with passages that are around the average difficulty level of the passages.

Although it seems more systematic in presenting the passages according to their difficulty, $N H W P$ is not an exception from the two textbooks. Flesch Grade Level scores for the reading texts in NHWP varied in the textbook. The estimated grades for the reading passages ranged from 8.8 (Grade eight) to 3.8 (Grade ten). The presentation of the reading passages was more systematic in light of their difficulty level as they began with relatively easy passages and in the middle of the textbook, they appeared more difficult, and at the end of the textbook they inclined to easier readability levels.

Second: Results related to the first research question.

The second question investigated the appropriateness of the reading material in AP11, AP12, and NHWP to the students' reading levels. This part involves the results of the students in a representative cloze test from each textbook.

As the researcher was obliged to use a representative text from each textbook, he used the passage which had its readability level closest to the average readability level of all the passages in each textbook. This created a difference in the number of the deletions in each test version. In order to make equivalent comparisons between the students' results in the three test versions, the researcher resorted to comparing the percentages of the students' results in each level.

The researcher calculated the frequencies of students' scores for categorizing them in the three tests (AP11, AP12, and $N H W P$ ) in three categories: Independent, Instructional, and Frustration. In addition to calculating the percentages for these three levels in light of the textbooks under study. The adjusted residual was also calculated to determine if there is a relation between the textbook and students levels (Independent, Instructional, and Frustration) using Chi Square Test for Independence. Table 4 presents the frequencies and percentages of cloze test scores in the three textbooks at the independent, instructional, and frustration levels. 
TABLE 4:

DISTRIBUTION OF STUDENTS AT THE INDEPENDENT, INSTRUCTIONAL, AND FRUSTRATION LEVELS AND RESULTS OF X2 TEST OF INDEPENDENCE REGARDING TEXTBOOK

\begin{tabular}{llllll}
\hline \multirow{2}{*}{ Text-Book } & \multirow{2}{*}{ Statistic } & Decision & & & \multirow{2}{*}{ Total } \\
\cline { 3 - 5 } & & Frustration & Instructional & Independent & \\
\hline \multirow{2}{*}{ AP11 } & Count & 204 & 39 & 31 & 274 \\
& \% within Text Book & 74.5 & 14.2 & 11.3 & 100.0 \\
& Adjusted Residual & -1.39 & -0.76 & 3.36 & \\
\hline \multirow{2}{*}{ AP12 } & Count & 240 & 45 & 15 & 300 \\
& \% within Text Book & 80.0 & 15.0 & 5.0 & 100.0 \\
& Adjusted Residual & 1.34 & -0.36 & -1.68 & \\
\hline \multirow{2}{*}{ NHWP } & Count & 240 & 54 & 16 & 310 \\
& \% within Text Book & 77.4 & 17.4 & 5.2 & 100.0 \\
& Adjusted Residual & 0.02 & 1.09 & -1.58 & \\
\hline \multirow{2}{*}{ Total } & Count & 68.4 & 138 & 62 & 884 \\
& \% within Text Book & 77.4 & 15.6 & 7.0 & 100.0 \\
\hline$\chi 2$ & N of Valid Cases & & Df & Sig. & \\
\hline 12.099 & 884 & & 4 & 0.017 & \\
\hline
\end{tabular}

Table 4 shows that there is a significant relation between the textbooks under study and students' reading levels. This is clearly noticed on the percentage of students' scores in the independent level in API1 which is way higher than in the other textbooks. In addition to showing the relation between students' reading levels and the textbooks, Table 4 represents the results of the cloze test scores at each instructional level for the students studying the three textbooks. Cloze test scores revealed that the highest numbers of students were at their frustration levels (AP11: $74.5 \%, A P 12$ : $80 \%$, and NHWP: $77.4 \%$ ). However, $11.3 \%$ of $A P 11$ students, 5\% of AP12 students, and 5.2\% of NHWP students could read the text at their independent level which means that they do not even need the help of their teachers to read the text. Based on Table 4, it can be concluded that $14.2 \%$ of AP11 students, $15 \%$ of AP12 students, and 17.4 of NHWP students were at their instructional level, meaning that they needed their teachers' help to read and understand the texts.

\section{DisCUSSION}

The discussion of the results is presented in two dimensions; first: the readability level of the reading passages in the three textbooks under study, second, the reading levels of the students.

\section{Readability levels}

The two readability indices used in this study indicated that the average reading level of the secondary stage reading texts used in this study is about the same as reading materials which typically would be used by native speakers in the ninth grade. Surprisingly, and contrary to the expected difficulty of the reading passages in the three textbooks, a comparison between the three textbooks shows that the secondary school textbooks (API1 and AP12) are, on average, about three grade levels higher in reading difficulty than the textbook of the university level (NHWP) whose difficulty is about the same as reading materials which typically would be used by native speakers in the fifth or sixth grades.

The Flesch Kincaid Grade Level Readability Formula rates $A P 11$ and $A P 12$ in the ninth grade reading level with $A P 12$ being more difficult whereas $N H W P$ is rated between the fifth and sixth grade levels. On the other hand, the Flesch Reading Ease Formula rates the three textbooks in the following order, AP11: Standard, AP12: fairly difficult, and NHWP: fairly easy. This result contradicts with the normal expectations that the university reading level is more difficult than that of the secondary school. Chall (1983) points out that when students progress from high school to college, they meet more difficult reading demands. Similar to the results of this study are those of Browne (1996) which indicated that high school reading texts appeared to be more difficult in terms of readability than the college texts. The findings of the current study agreed with Williamson (2008) whose study showed that high school reading material reflected a substantially higher text demand than the texts in the postsecondary life.

It is worth pointing out that readability scores for the texts also varied tremendously within each textbook, and that neither of the textbooks followed a systematic pattern in presenting the passages in the textbooks according to their difficulty. Furthermore, the length of texts seems to be another factor that is not given an appropriate attention in the three textbooks. The pattern of the passage length for the reading comprehension in the textbooks is highly irregular. Only very few passages in each textbook are at the same length. Therefore, within the Jordanian EFL secondary reading context, the gap between the length of the passages used at the secondary school level and the length of the reading texts that the students are expected to read at the university level should be reconsidered in order to help preparing secondary students for reading in English at the university level. Although it is supposed that the reading texts within a textbook should have a pattern of difficulty and length, some scholars indicated that this is not the case with all reading materials. For example Roe, Stoodt, and Burns (1978) reported that evidence indicates that a wide range of variety of difficulty exists with single texts and that many texts do not have a gradation of difficulty from the beginning to the end.

In spite of the importance of readability which entails ordering the reading texts according to their difficulty, it is likely that readability issues have not been taken into consideration when the three textbooks were written or adapted. The readability results mostly show that the reading content in the three textbooks did not follow any pattern according 
to readability statistics. Crawly and Mountain (1995, p.22) indicate that "the readability level should be a determining factor in choosing a particular book".

\section{Students' reading levels}

The results in this part show that there is a significant relation between the textbooks under study and students' reading levels. This is clearly noticed on the percentage of students' scores in the independent level in APII which is way higher than in the other textbooks. The cloze test scores revealed that the majority of the students were at their frustration levels (AP11: 74.5\%, AP12: 80\%, and NHWP: 77.4\%). However, the results of the cloze tests indicate that the percentage of the students who could read the reading texts in the three textbooks (students who scored higher than $40 \%$ ) was $25.5 \%$ for $A P 11,20 \%$ for $A P 12$, and $22.6 \%$ for $N H W P$.

The readability statistics (Flesch Reading Ease and Flesch Kincaid Grade level) rated the three textbooks under the grade levels of the students who study each of the textbooks. These statistics were mainly used in this study for the purpose of comparing the readability levels of these textbooks. For more profound results, cloze tests were used to relate the readability of the textbooks to the reading levels of the students who are using them. In spite of the low readability levels of the three textbooks shown by the readability indices, the cloze test scores indicated that the three textbooks are very difficult for the students who study them and that very little percentage of the students may profit from the reading passages in the textbooks.

The results of this study confirm the findings of some earlier studies (Harris-Sharples, 1983; Reed, 1987) which found that the studied textbooks had higher readability levels than students' average achieved reading score. The results also agreed with Sellars (1987) whose study showed that $92 \%$ of the high school tested students were all at the frustration reading level and only $8 \%$ of the subjects were able to profit from attempting to read the textbooks. The study also agreed with Reed (1988) where the high school textbooks were too difficult for the levels of the students, more difficult even than the college texts in terms of readability. Locally, the study agreed with the results of the study of Masri (2006) which also found that most students were unable to read "Jordan Opportunities" even with the help of the teacher. The findings of the current study disagreed with Ulusoy (2006) where cloze test results showed that half of the students were reading at their instructional level. However, it is worth pointing out that unlike most of the previous studies, Ulusoy's study was conducted on Turkish first language materials and students.

Most of the previous studies indicate that there are several textbooks in use which are written at a readability level above that of the grade for which they are intended. This study has shown that a large percentage of its student sample is unable to effectively read the reading passages in the assigned textbooks. These results strongly suggest that when selecting a textbook, not only the readability level of the textbook should be considered, but also the reading ability of the students for whom the textbook is selected.

\section{CONCLUSION}

A comparison between the readability statistics of the three textbooks shows that the secondary school textbooks are more difficult, in terms of readability of the reading passages, than the university level textbook. This result contradicts with the normal expectations that the university reading level is more difficult than that of the secondary school. Furthermore, the readability statistics show that neither of the textbooks followed a systematic pattern in presenting the passages in the textbooks according to their difficulty. The presentation of the reading passages begins almost with the most difficult passage and ends with below-the-level passage. As the readability results mostly show that the reading content in the three textbooks did not follow any pattern according to readability statistics. On the other hand, the cloze test scores revealed that the majority of the students were at their frustration levels. In spite of the low readability levels of the three textbooks shown by the readability indices, the cloze test scores indicated that the three textbooks are very difficult for the students who study them and that very little percentage of the students may profit from the reading passages in the textbooks. These results strongly suggest that when selecting a textbook, not only the readability level of the textbook should be considered, but also the reading ability of the students for whom the textbook is selected. The results also show that it is likely that readability issues have not been taken into consideration when the three textbooks were written or adapted. The researcher recommends that procedures of testing the readability and the suitability of the reading material to the students should be used to investigate the difficulty and gradation of the textbooks in addition to their appropriateness to the levels of the learners.

\section{REFERENCES}

[1] Abdulla, H., Hashim, R. (2007). Readability analysis of Malaysian short stories in English. Journal E-Bangi, 2, 2 , 1-11. Retrieved November $6^{\text {th }} 2011$ from http://pkumweb.ukm.my.

[2] ACT, Inc. (2006). Assessing the college readiness in reading of eighth- and ninth-grade students using ACT's EXPLORE®. Iowa City, IA: Author. Retrieved December 29 ${ }^{\text {th }}, 2012$ from Academic Search Premier EBSCO Database (AN: ED510538).

[3] Browne, C. (1996). Japanese EFL reading texts: How readable are they? Working Papers in Applied Linguistics, 8, 1-12.

[4] Chall, J. (1983). Stages of reading development. New York: McGraw-Hill Book Co.

[5] Crawley, S., Mountain, L. (1995). Strategies for Guiding Content Reading. Boston: Allyn and Bacon.

[6] Harris- Sharples, D. (1983). A study of the match between students reading ability and textbook difficulty during classroom instruction. Unpublished PhD dissertation, Harvard University, Harvard. Retrieved January $20^{\text {th }}, 2012$ from Proquest database. 
[7] Harrison, C. (1980). Readability in the classroom. Cambridge: Cambridge University Press.

[8] Hussein, B. (2012). Analysis of the real situation of teaching reading comprehension to first year Students at the Department of English Language and Literature at Al-Zaytoonah Private University of Jordan. Asian Social Science 8. 4, 237-253.

[9] Macklin, M. (1978). Content area reading as a process for finding personal meaning. Journal of Reading, 22, $211-213$. Retrieved October $24^{\text {th }} 2011$ from Academic Search Premier EBSCO database (AN: EJ 195997).

[10] Masri, A. (2006). The Readability level of English textbooks of the tenth grade and its relationship to students' gender and area of residence. Unpublished Master Thesis, Mu'tah University, Karak, Jordan.

[11] Reed, K. (1987). An analytical comparison of reading levels of junior college students with the readability levels of textbooks used in content area courses. Paper presented at the Annual Conference of the Postsecondary Reading Council of Alabama. February 12, 1987. Retrieved Novemder 17 $7^{\text {th }}, 2011$ from Academic Search Premier EBSCO database (AN: ED 284177).

[12] Renaissance Learning. (2011). Matching books to students: how to use readability formulas and continuous monitoring to ensure reading success. Wisconsin Rapids, WI: Author. Available online from http://doc.renlearn.com/KMNet/R001438603GC81D6.pdf (accessed 12/3/2012).

[13] Roe, D., Stoodt, R., Burns, C. (1978). Reading instruction in the secondary school, Revised edition. Chicago: Rand McNally College Publishing Co.

[14] Sellars, G. (1987). A comparison of the readability of selected high school social studies, science, and literature textbooks. Unpublished PhD dissertation: The Florida State University. Retrieved October $13^{\text {th }}, 2011$ from Proquest database.

[15] Sidek. H. (2011). Methods of EFL secondary instruction: preparation for higher education. International Journal of Humanities and Social Sciences, 1(3), 181-191.

[16] Tabatabaei, E., \& Bagheri, M. (2013). Readability of Reading Comprehension Texts in Iranian Senior High Schools Regarding Students' Background Knowledge and Interest. Journal of Language Teaching and Research, Vol, 4, No 5, 1028-1035.

[17] Ulusoy, M. (2006). Evaluation of textbook difficulty and adaptation strategies used in Turkish elementary schools. Unpublished $\mathrm{PhD}$ dissertation, University of Illinois at Urbana- Champaign. Retrieved October13 ${ }^{\text {th }}, 2011$ from Proquest database.

[18] Venezia, A., Krist, M., \& Antonio, A. (2003). Betraying the college dream: how disconnected K-12 and postsecondary education systems undermine students' aspirations. Stanford, CA: Stanford Institute for Higher Education Research. Retrieved February 13th, 2012 from http://www.stanford.edu/group/bridgeproject/betrayingthecollegedream.pdf.

[19] Wilkins, C., Hartman, J., Howland, N., \& Sharma, N. (2010). How prepared are students for college-level reading? Applying a Lexile ${ }^{\circledR}$ based approach. Regional Educational Laboratory. Retrieved October $19^{\text {th }} 2011$ from Academic Search Premier EBSCO database (AN: ED 513585).

[20] Williamson, G. L. (2008). A Text Readability Continuum for Postsecondary Readiness. Journal of Academics, 19 (4), $602-632$. Retrieved June $17^{\text {th }} 2011$ from Academic Search Premier EBSCO database (AN: EJ 822324).

Nasser M. Freahat is an assistant professor of English Language Curricula and Instruction. He is teaching English language courses for graduate and undergraduate courses in the English Language Department at Imam Mohammad Ibn Saud Islamic University-Riyadh, Saudi Arabia. His research interests include Language Acquisition, Teaching Reading Comprehension, Discourse Analysis. 